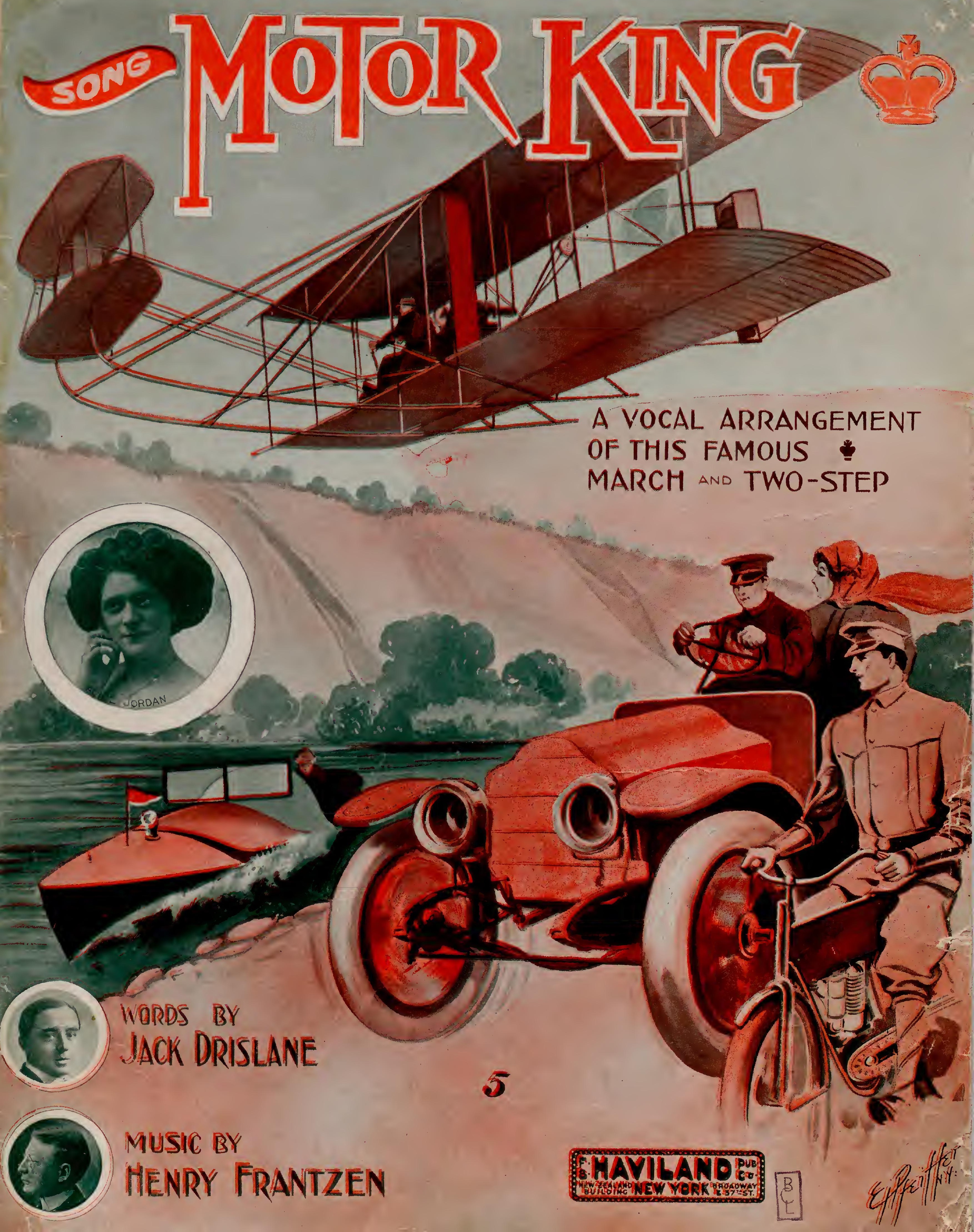


THREE BIG SONG SUGGESSES!

WOrdS bY JACK DRISLANE. You'il Come Back.

Musle by GEO. W. MEYER.

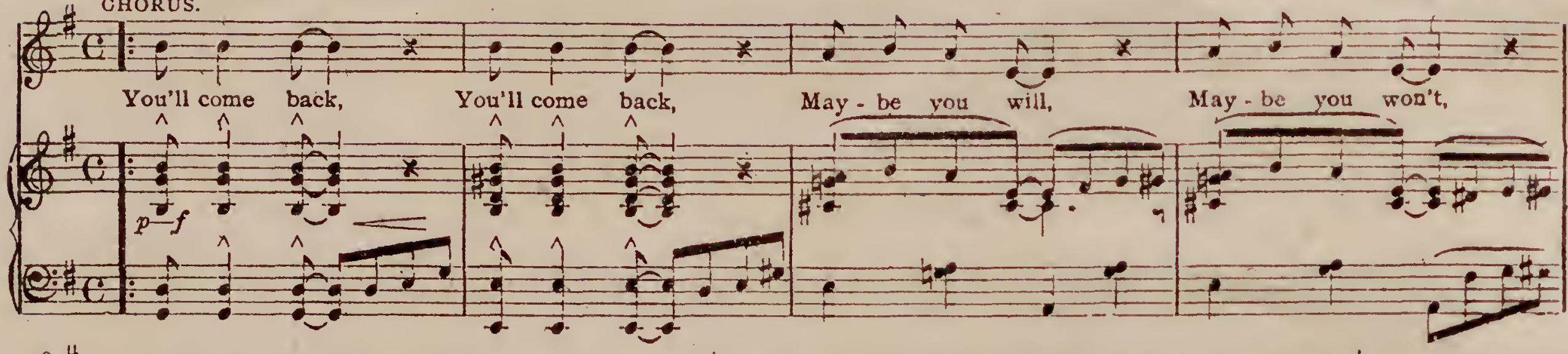

You'll come back and hang a - round that old ve - ran - da, You'll come backand beg my par -don, A - lex - an. de -

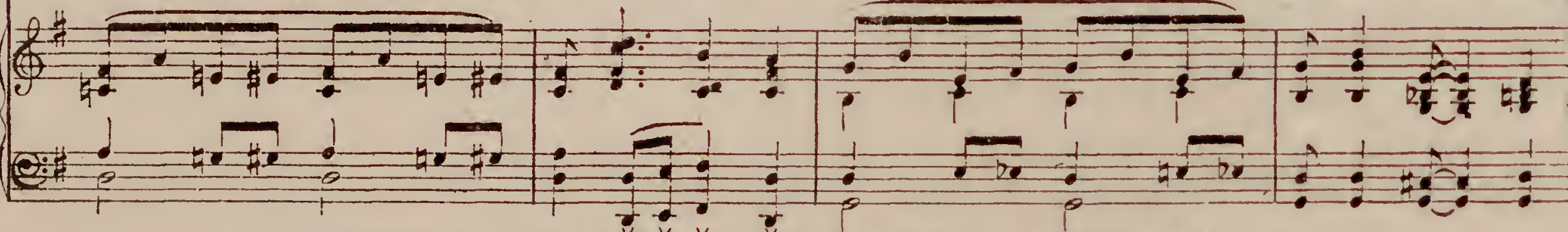

Copyright, 1909, by F. B. Haviland Publishing Co., Inc., 125 W. 37th St, N. Y. International Copyright Secured.

Words bY JACR DRISLANE.

That Qhinatoron Rag.
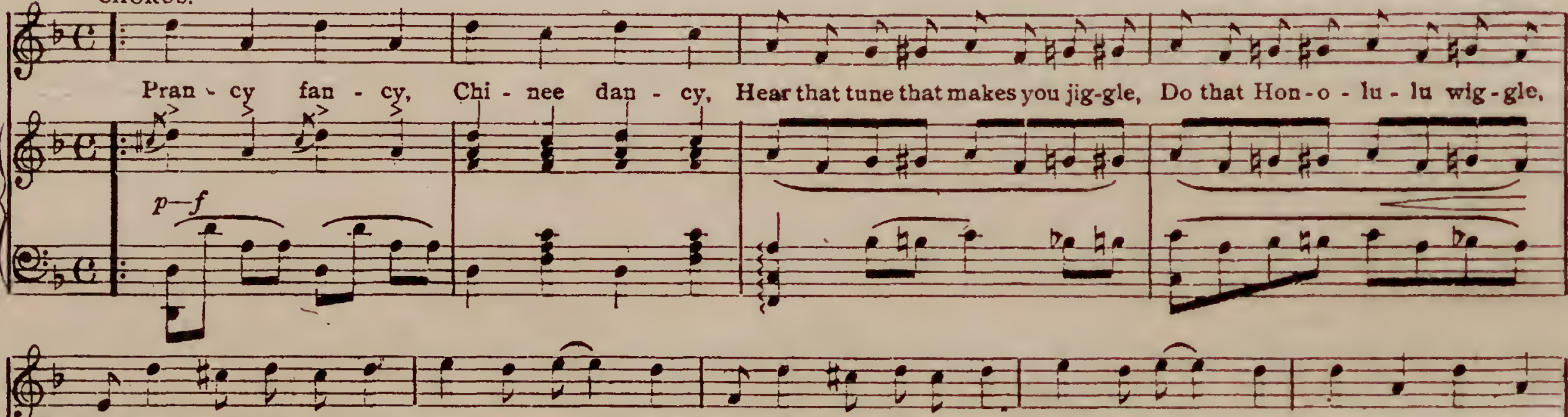

(Sho) Kiss me and call me yoúr mam-ma, mam - ma, Tell me that I am your Ya-ma, Ya - ma; Slide- Y, Glide - $Y$,

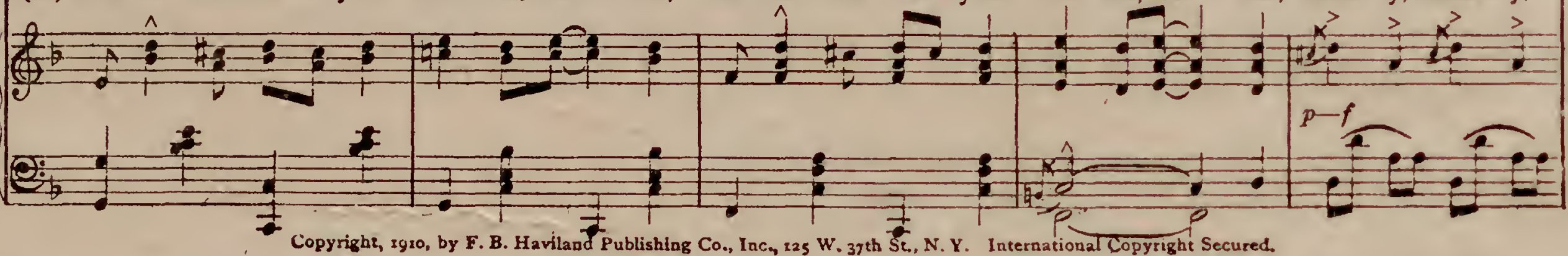

That Firssy Rag.

(Ob You-Rag.) Words \& Musie by VICTOR H. SMaLLEY.

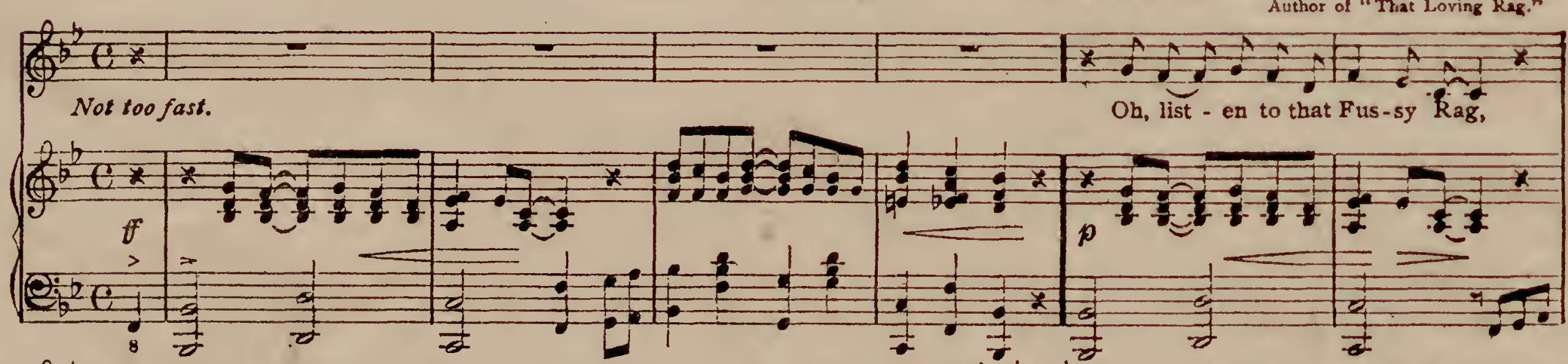

tre. Ob, list - en to that joy-ful jag,

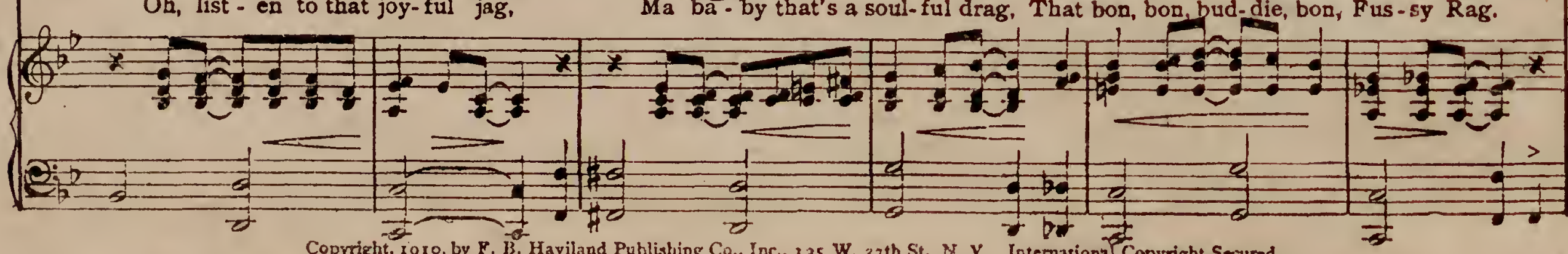




\section{Motor King.}

Words by

Song.

JACK DRISLANE

Music by

HENRY FRANTZEN
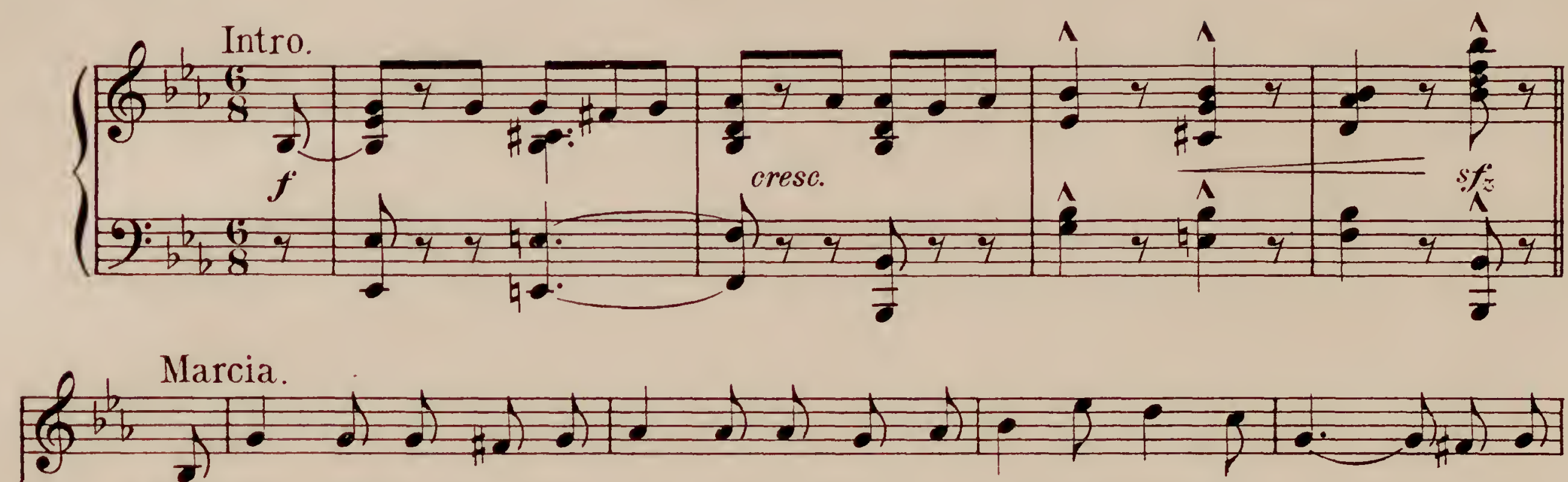

1. They talk of things in the line of kings, there's a king that beats them all__ They don't 2. The crowdsturn out just to cheer and shout, when he en-ters in a race,_ F For they
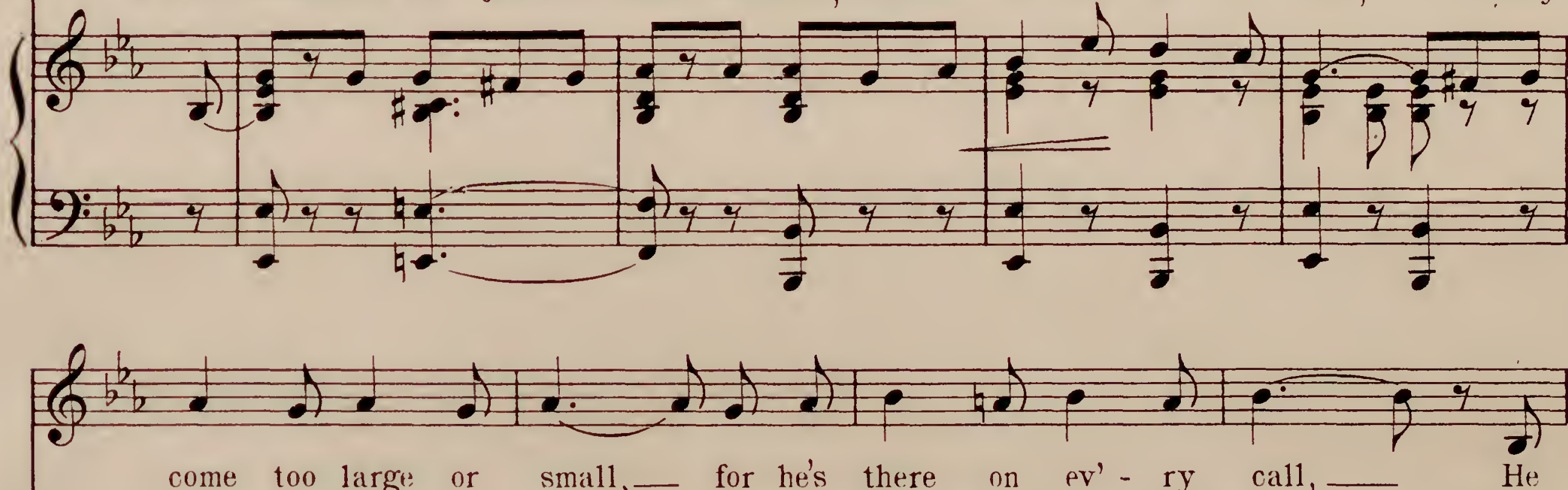
know he sets a pace _ that will keep him in first place,___ They
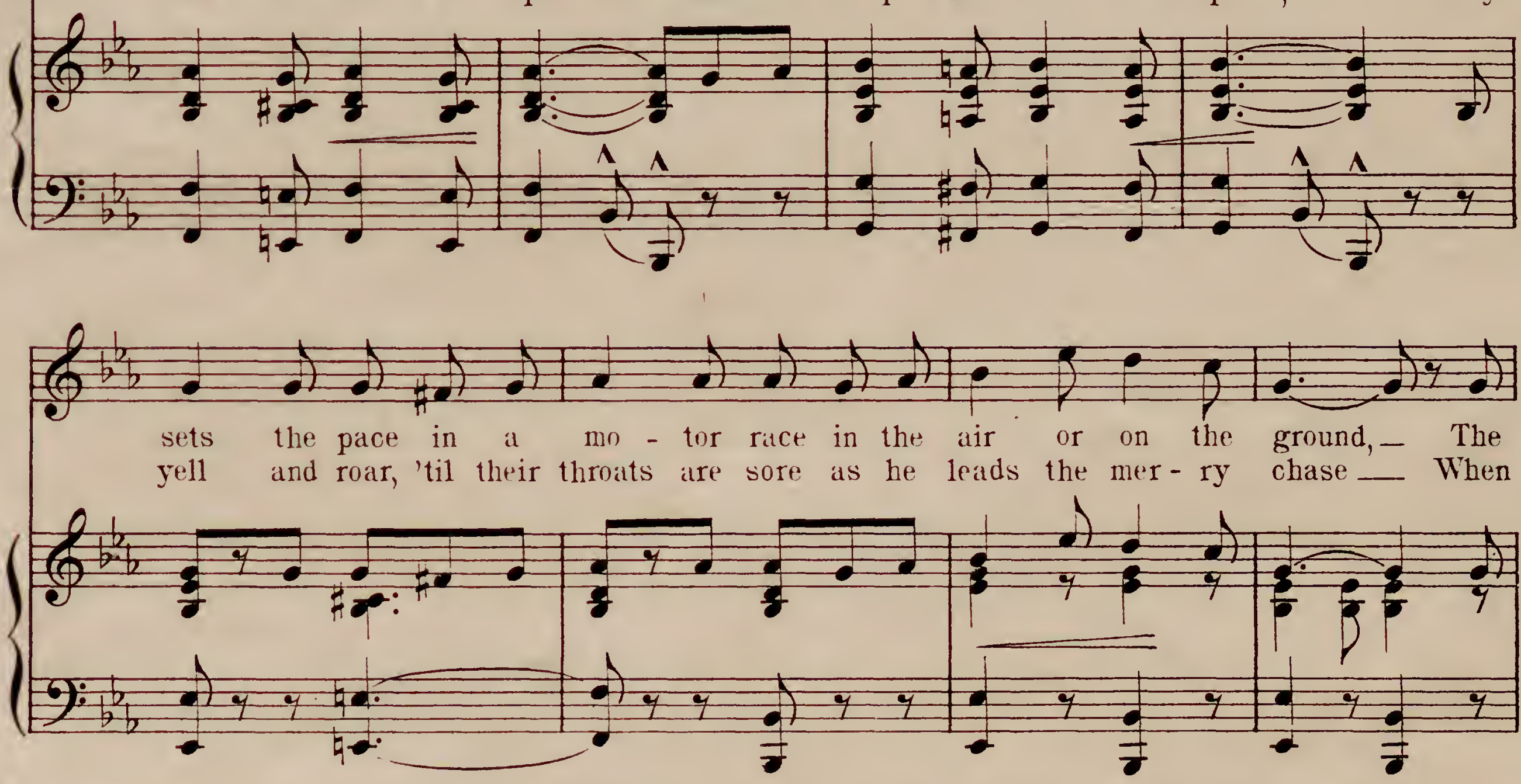

Copyright 1910 by F. B. Haviland Pub.Co.Inc. 125 W. 37 th St.,New York. Internatinnal Copyright Secured.

Little Tunes for little folks Nọs 1 \& 2 these folios contain 11 Complete easy Classies in grades 2 and 3 with foreign fingering Price 254 each Postpaid. 

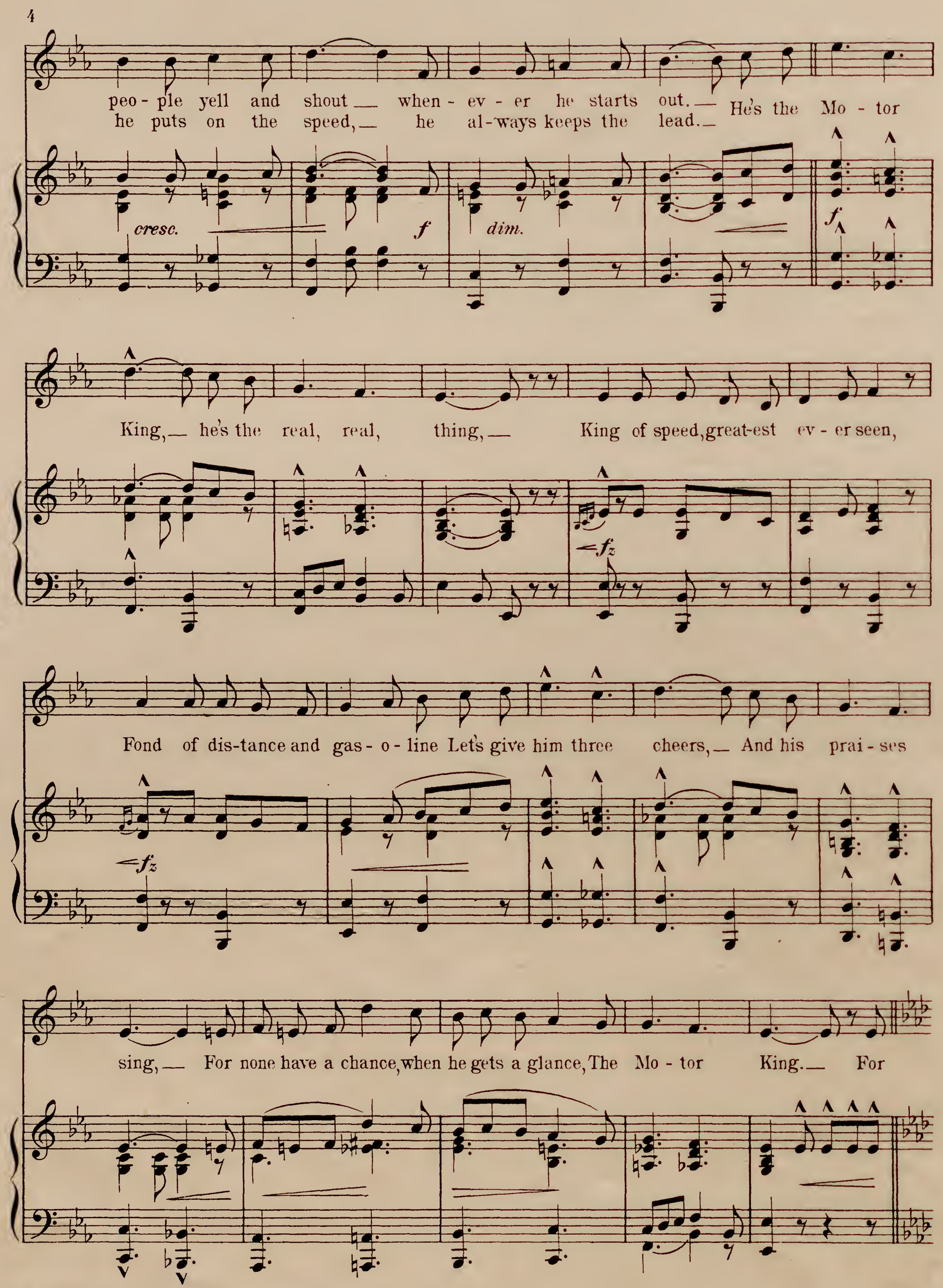

Motur King 5

Haviland's Dance folios for piano solo Nợ 1-2-3-4-5-4-7 and 8 These folios contain our late \& popular song successes Arranged for piano for dancing Price 25\$ each postpaid. 
Chorus.
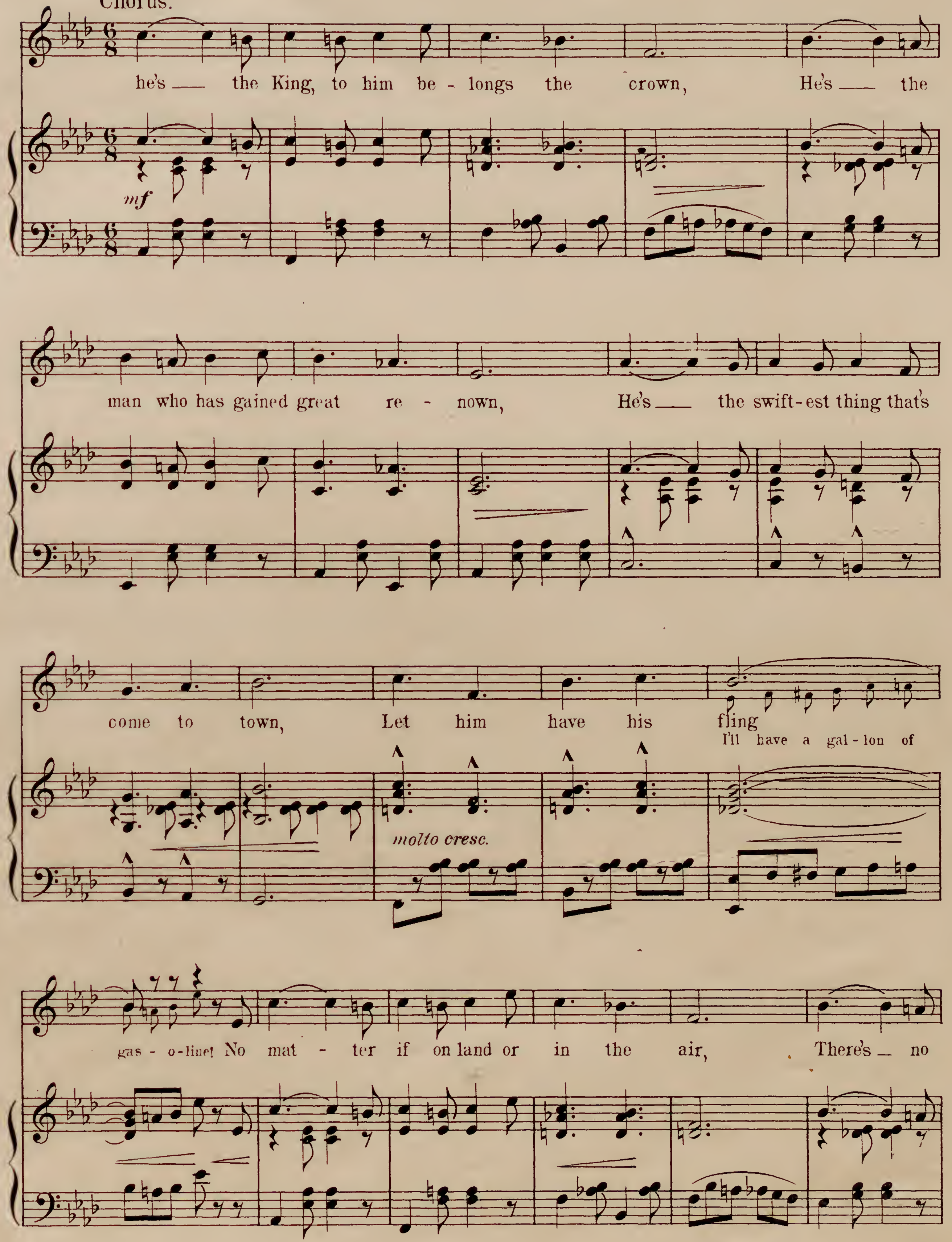

Motor King 5 

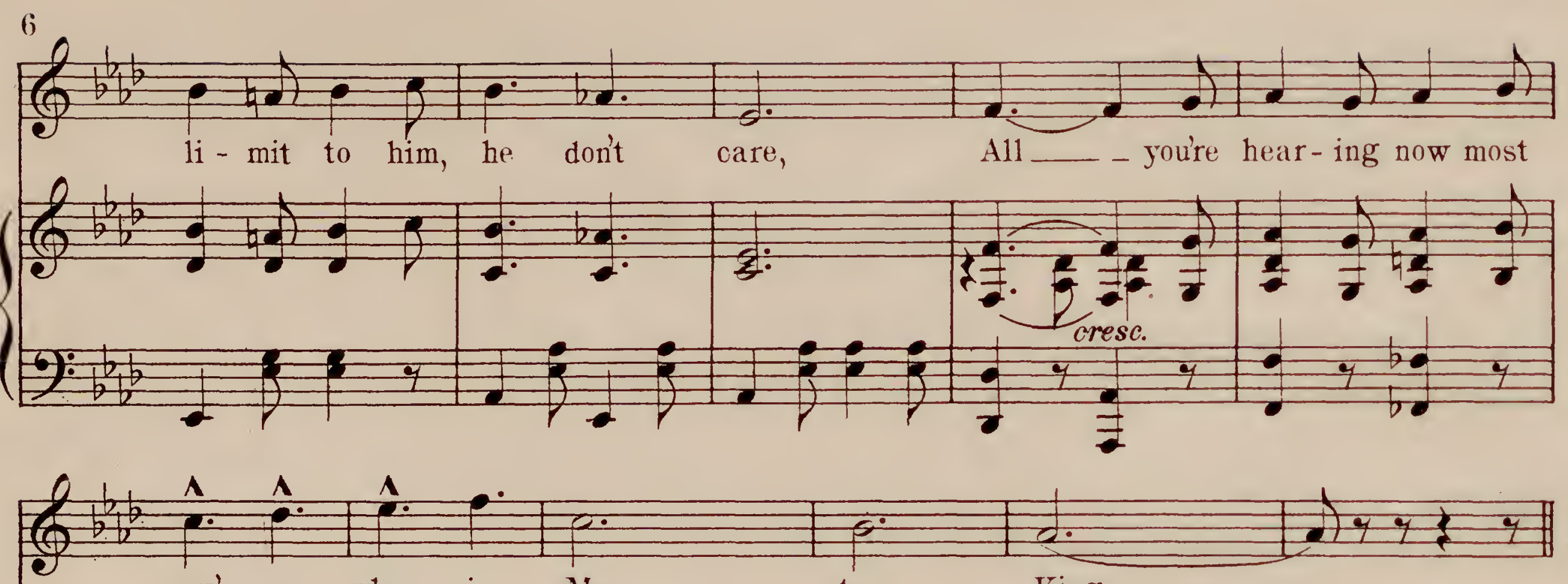

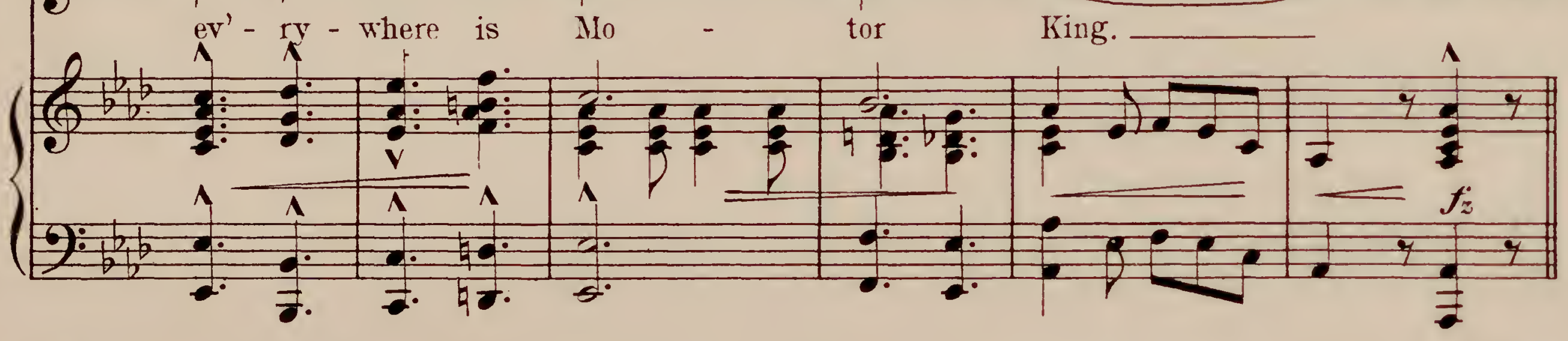

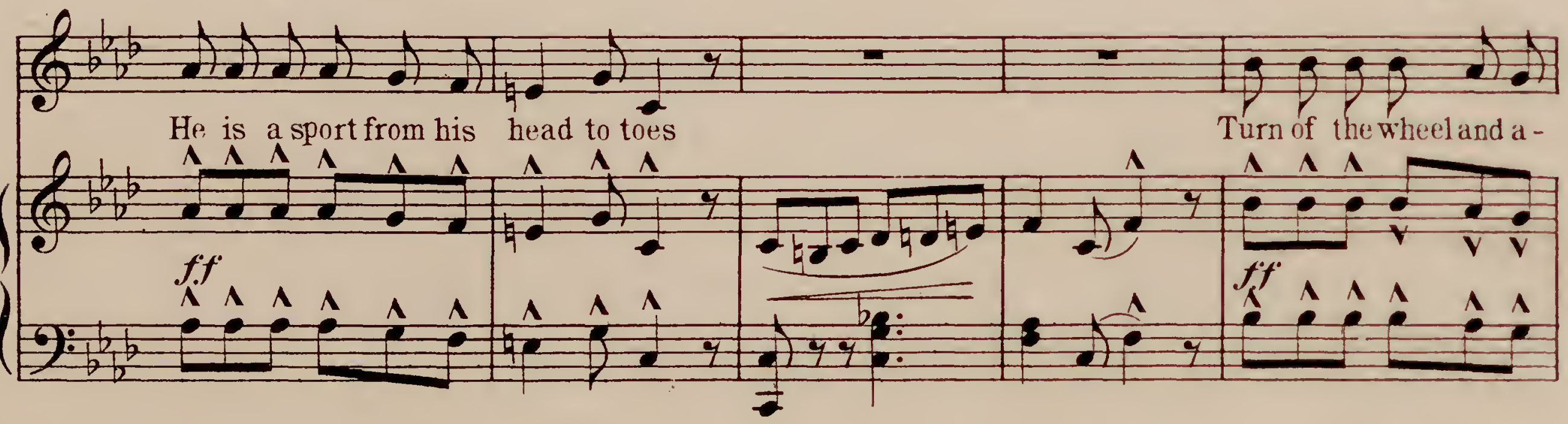

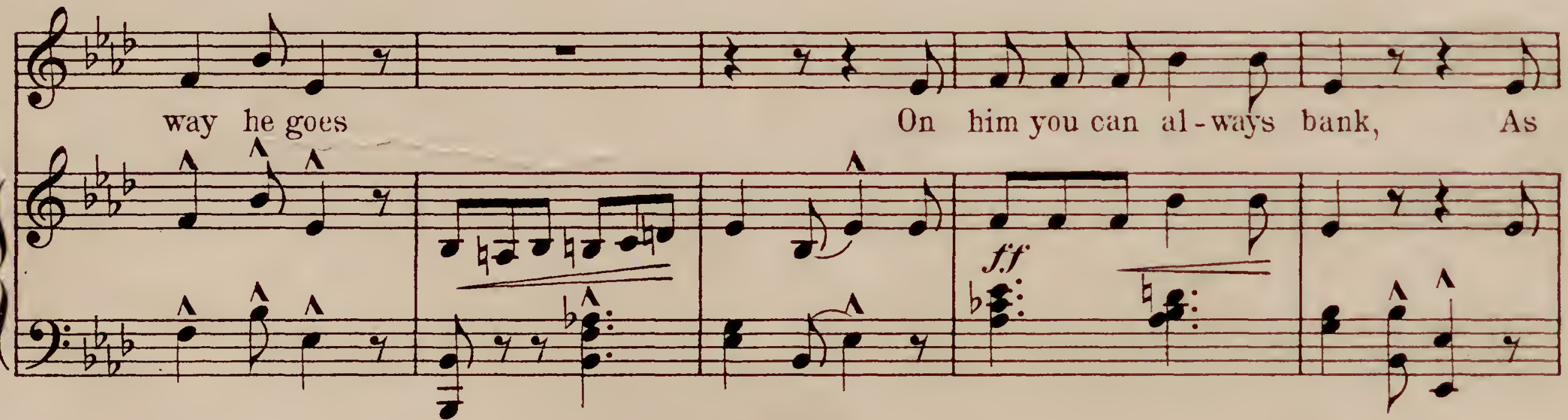

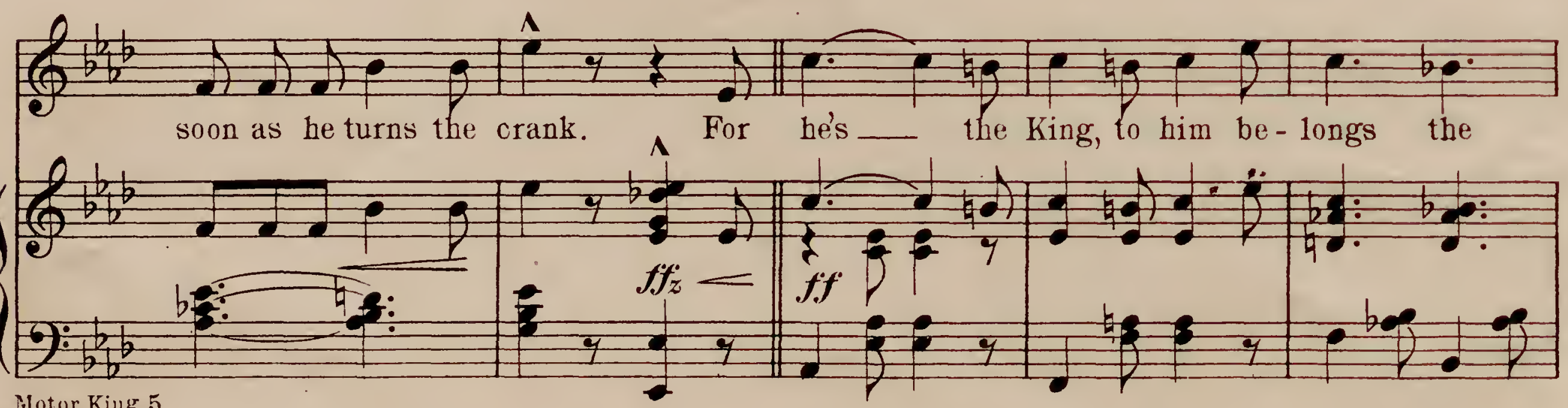



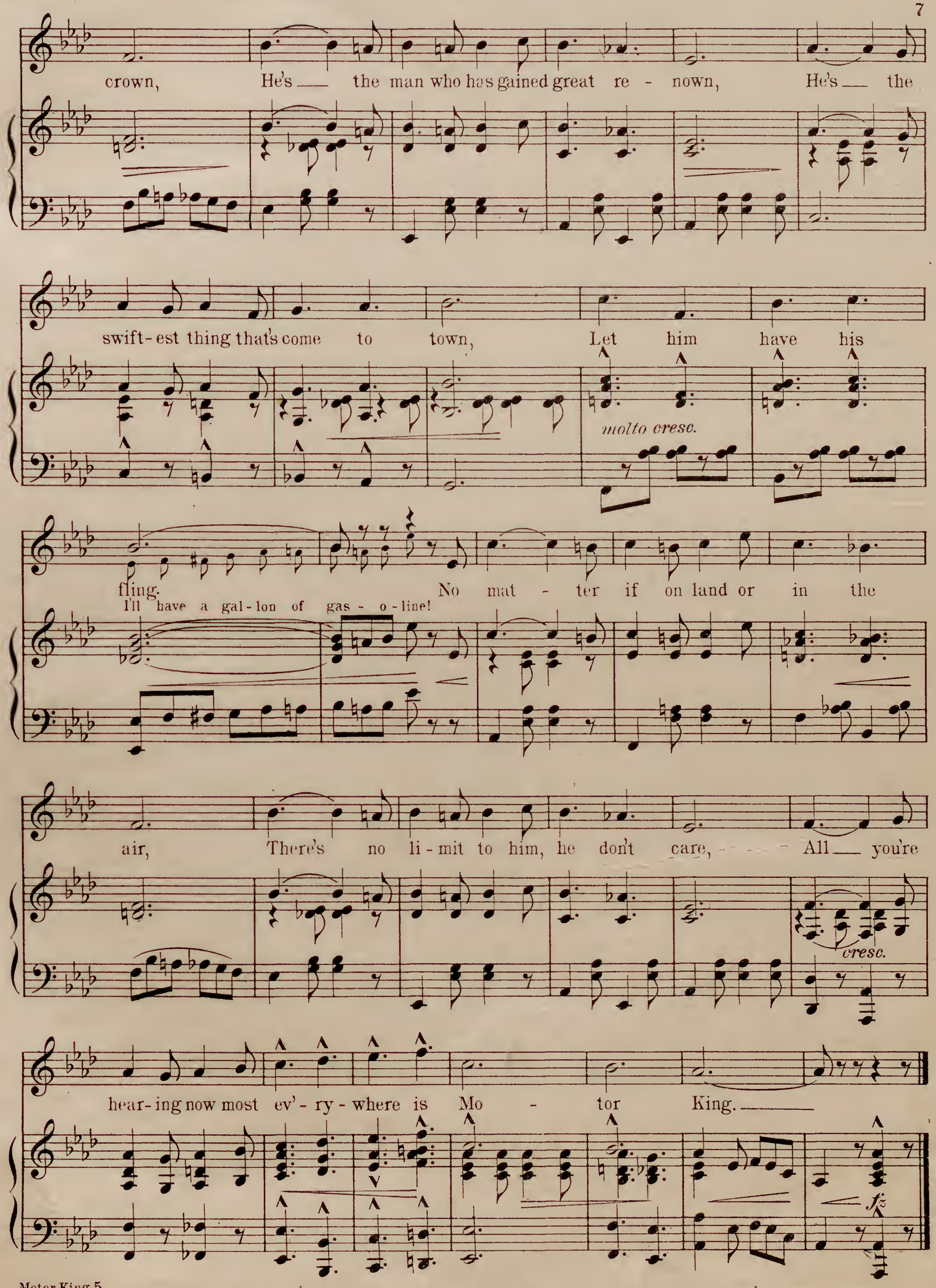

Motor King 5

"You'll Come Back," a coon song, which is better than "Bill Bailey Won't You Please Come Home," featured by the best Vaudeville artists on the American stage. 


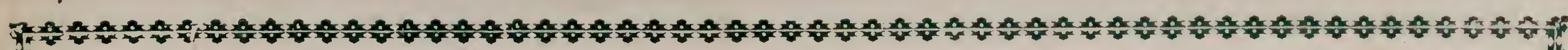
THE BIGGEST OF ALL BALLAD SUCCESSES

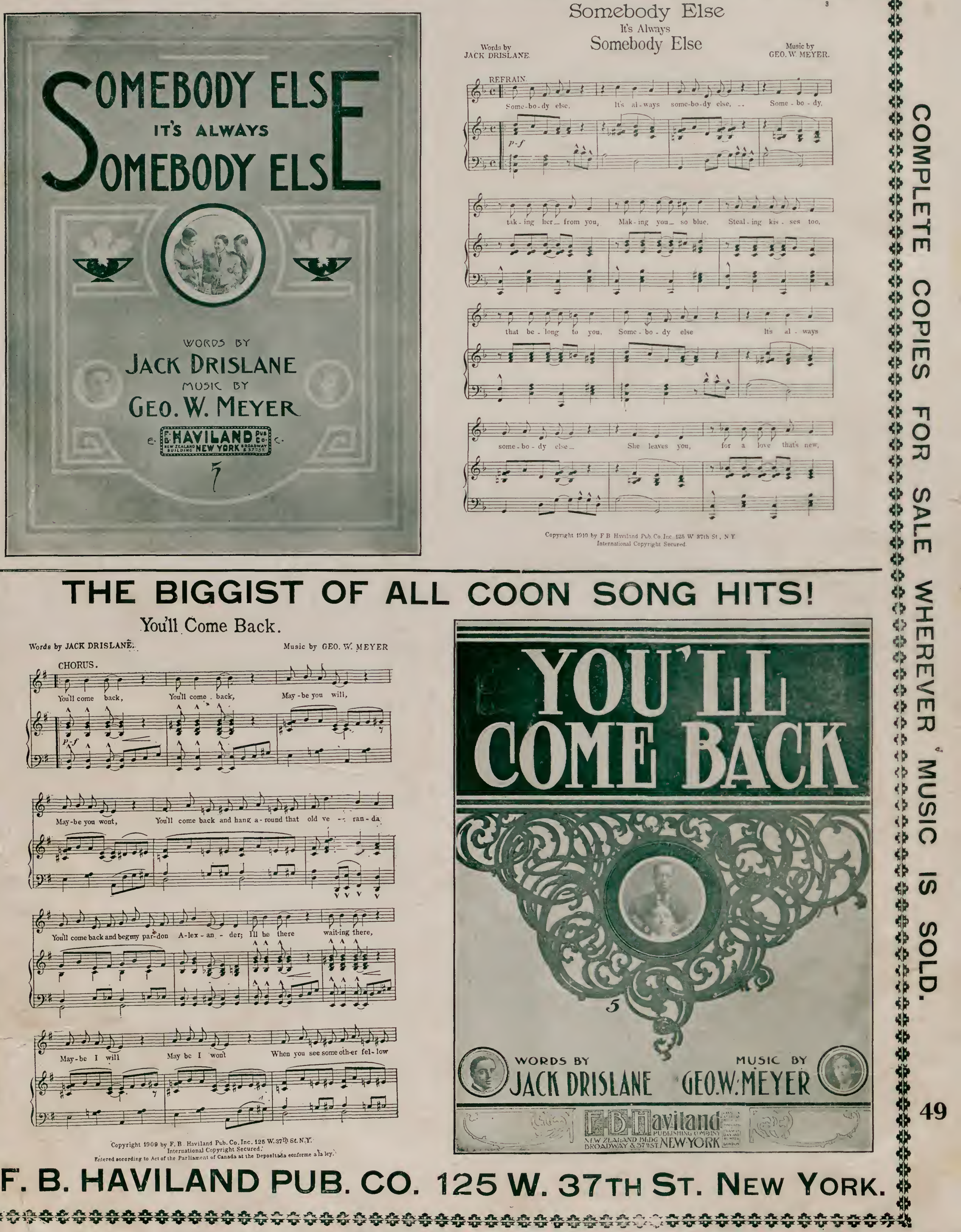

